DOI: $10.4274 /$ jarem.galenos.2019.2853

J Acad Res Med 2020; 10(1): 57-63

\title{
Recurrent Admissions to Psychiatric Emergency Service: What are the Needs of the Elderly in This Area Differing from Young People and What Can be Done? A Retrospective Comparative Study
}

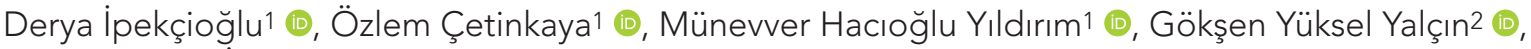

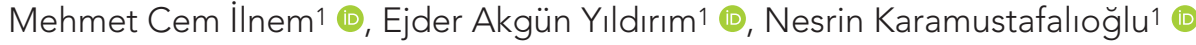 \\ ${ }^{1}$ İstanbul Bakırköy Prof. Dr. Mazhar Osman Mental Health and Neurological Diseases Training and Research Hospital, Clinic of Psychiatry, İstanbul, Turkey \\ ${ }^{2}$ Acıbadem Bakırköy Hospital, Clinic of Psychiatry, İstanbul, Turkey
}

Cite this article as: İpekçioğlu D, Çetinkaya Ö, Hacıoğlu Yıldırım M, Yüksel Yalçın G, İlnem MC, Akgün Yıldırım E, Karamustafalığlu N. Recurrent Admissions to Psychiatric Emergency Service: What are the Needs of the Elderly in This Area Differing from Young People and What Can be Done? A Retrospective Comparative Study. JAREM 2020;10(1): 57-63

\begin{abstract}
Objective: Recurrent admissions to psychiatric emergency services (PES) are a multidimensional clinical situation. In this situation, elderly people have different properties and needs compared to younger people. The aim of the present study was to determine the characteristics and needs of the elderly people with recurrent admissions to PES in terms of sociodemographic, clinical characteristics and clinical approach, according to the different features of the youth, and to draw attention to what can be done.

Methods: The files of the patients aged 18 years and over, who had two or more admissions to our hospital's PES between January 2011 and January 2012, were examined by random method (one in 23 patients). A total of 324 patients were included in this retrospective comparative study. The patients were divided into two groups as those aged 65 years and older (elderly group, $n=167$ ) and those aged 18-65 years (young group, $n=157$ ) and compared as per the findings obtained.

Results: As per the young people, the elderly often applied to the PES with family members; the rate of physical disease was higher; more physical examinations and consultations were requested during the evaluation of the elderly; visual hallucination, memory impairment, and verbal violence were found to be higher in the symptom profiles. The most common diagnoses of the elderly were determined to be psychosis, behavioral and psychological symptoms related to dementia, bipolar mood disorder, depression and anxiety disorder, and the hospitalization was found to be lower in the elderly.

Conclusion: Elderly patients differ from young people in terms of physical disease comorbidity, physical examination, consultation request, symptom profile, diagnosis and treatment plan. The evaluation of the elderly patient will provide a multidisciplinary approach, the formation of professional teams in the field should be the main purpose. In this way, recurrent admissions of elderly people to PES can be prevented.

Keywords: Psychiatric emergency service, recurrent admission, age, psychiatric disease
\end{abstract}

\section{INTRODUCTION}

The proportion of the elderly population (65 years and over) in the total population in our country increased from $7.7 \%$ in 2013 to $8.5 \%$ in 2017. This rate is estimated to be $16.3 \%$ in 2040 (1). In parallel with the increase in the elderly population, psychiatric emergency services (PES) will be an important clinical need to meet the needs of this group of patients.

ORCID IDs of the authors: D.I. 0000-0001-6143-5671; Ö.Ç. 0000-0003-3919-1054; M.H.Y. 0000-0001-5241-1619; G.Y.Y. 0000-0001-9961-4464; M.C.I. 00000003-1614-9056; E.A.Y. 0000-0002-8620-1254; N.K. 0000-0002-2825-3240. 
The definition of recurrent admission to PES in the literature differs. There are different definitions on 2 admissions to PES within one year, six or more admissions within one year or at least three admissions within one year (2-4). Recurrent admissions constitute $1 / 3$ of PES admissions. A good understanding of the sociodemographic and clinical characteristics of these patients will contribute to the improvement of mental health services $(3,5,6)$. The recurrent admission rate to PES ranges between 5 and $56 \%$. Those with recurrent admissions have more chronic social problems than those with single admissions (7).

Detecting the diagnostic, demographic and social characteristics of PES admissions in the elderly group, who require special interest and knowledge in the field of psychiatry, will better determine the role and structure of future geropsychiatric emergency health care provision (8). Despite the fact that PES is an important point of admission for the elderly in reaching mental health services and researchers in the field of health are working on the adequacy of health care services for the elderly, the general interest in PES is insufficient. Research should be carried out in order to create recommendations that may be a guide in PES planning and implementation. In order to overcome the deficiencies in PES, it is necessary to increase the quality of health services, to increase education in this area, to develop PES, to standardize and to encourage research. In this way, the future crises to be given to the elderly in future mental health services can be prevented $(9,10)$.

Unlike the young people, the reasons for remitting referral to PES and determining the needs in this area are important factors in effective interventions to prevent recurrent admissions, measures to be taken before the admission, management of the admission process and the post-admission is thought to be important in planning health

\section{METHODS}

The files of the patients aged 18 years and over, who had two or more admissions to our hospital's PES between January 2011 and January 2012, were examined by random method (one in 23 patients). A total of 324 patients (167 elderly, 157 young) were included in this retrospective comparative study. Data were recorded to the data screening form prepared by the researchers, which included sociodemographic and clinical characteristics prepared by the researchers (age, gender, education level, marital status, social security, working status, with whom they live, smoking, alcohol, psychoactive substance use, physical illness), admission to PES, evaluation and treatment. In the data screening form including psychiatric diagnoses according to Diagnostic and Statistical Manual of Mental Disorders-4 diagnostic criteria, the characteristics (number of admissions, number of visitors, admission form, admission for drug printing, physical examination, consultation, emergency treatment, treatment plan, treatment arrangement), clinical signs and symptoms and diagnoses were recorded. The patients were divided into two groups as those aged 65 years and older and those aged 1865 years, and compared with respect to these characteristics.
Ethical committee approval was obtained from the Local Ethics Committee of İstanbul Bakırköy Prof. Dr. Mazhar Osman Mental Health and Neurological Diseases Training and Research Hospital (approval number: 6779, date: 03.02.2014).

\section{Statistical Analysis}

SPSS 18 program was used for statistical analysis of data. To determine the statistical significance between the groups, numerical data were evaluated by the t-test and other data by the chi-square test. The chi-square for normally distributed data and the Fisher's exact for non-normally distributed data were performed. $\mathrm{P}<0.05$ was considered statistically significant.

\section{RESULTS}

When elderly group and young group were compared in terms of sociodemographic and clinical features, the female gender ratio was higher in the two groups $[(57.5 \%(n=96)$ in the elderly group and $52.2 \%(n=82)$ in the young group]. When the two groups were compared, the rates were as follows in the old and young groups, respectively; $91 \%$ vs $58 \%$ for those receiving education between 0 and 5 years, $98.8 \%$ vs $92.3 \%$ for those who had social security, $5.4 \%$ vs $33.8 \%$ for smoking, $4.2 \%$ vs $29.3 \%$ for working life, $1.8 \%$ vs $10.8 \%$ for alcohol use, $3 \%$ vs $8.9 \%$ for psychoactive substance use, and $50.3 \%$ vs $10.8 \%$ for additional physical disease. According to the mentioned characteristics, the elderly showed a statistically significant difference $(p<0.05)$ than the young. The sociodemographic and clinical characteristics are summarized in Table 1.

When we compared the groups in terms of admission to PES, evaluation and treatment characteristics were as follows: elderly people were more frequency admitted to the emergency unit with family members ( $82.6 \%$ vs $36.9 \%)$, had more physical examinations $(7.2 \%$ vs $1.3 \%$ ), consultations (19.8\% vs $3.2 \%$ ) and planned outpatient follow-up visits to emergency service $(75.4 \%$ vs $65.6 \%$ ). In addition, more recipe was prescribed for the elderly during emergency discharge (68.3\% vs $44.6 \%$ ). According to the mentioned characteristics, the elderly showed a statistically significant difference $(p<0.05)$ than the young except planned outpatient follow-up visits $(p<0.052)$. According to the mentioned characteristics, the elderly showed a statistically significant difference $(p<0.05)$ than the young. The admission to PES, evaluation and treatment characteristics are summarized in Table 2.

When we compared two groups in terms of the symptom profile, it was found that visual hallucinations ( $7.8 \%$ vs $1.3 \%)$, memory impairment $(7.8 \%$ vs $0 \%$ ), and verbal violence $(33.5 \%$ vs $17.8 \%$ ) were significantly higher in the elderly group than in the young group. Disease duration, clinical symptoms and findings are summarized in Table 3.

In turn, the rates of diagnoses in the elderly were $24.6 \%$ for psychosis, $23.4 \%$ for behavioral and psychological symptoms related to dementia, $19.2 \%$ for bipolar mood disorder, $17.4 \%$ for depression, $12 \%$ for anxiety disorder, $1.8 \%$ for adverse effects of drug use, $1.2 \%$ for mental retardation and behavior problems, and $0.6 \%$ for substance use disorders. The diagnostic distribution 
showed a statistically significant difference between the two groups $(p<0.05)$. The distribution of psychiatric diagnoses is summarized in Table 4.

\section{DISCUSSION}

In our study, we defined recurrent admissions as two or more admissions to PES per year. There is no consensus among the researchers about the definition of recurrent admission to PES. This situation does not cause any problem about the definition of recurrent admission in our study. In 2012, the average number of admissions per day to PES of our hospital was 77. Between January 2011 and January 2012, a total of 28359 people were admitted to PES. Among these admissions, the rate of two and more admission is $26.8 \%$ (7505). In the studies, the rate of recurrent admission to PES was reported to be between 21 and

\begin{tabular}{|c|c|c|c|c|}
\hline & & $\begin{array}{l}65 \text { years } \\
\text { and over } \\
(n=167)\end{array}$ & $\begin{array}{l}\text { Between } \\
18-64 \\
(n=157)\end{array}$ & $p$ \\
\hline \multicolumn{2}{|l|}{ Age } & $72.69 \pm 7.35$ & $36.94 \pm 10.66$ & $0.001^{* * *}$ \\
\hline \multirow{2}{*}{ Gender } & Female & 96 (57.5\%) & 82 (52.2\%) & \multirow{2}{*}{0.342} \\
\hline & Male & 71 (42.5\%) & 75 (47.8) & \\
\hline \multirow{3}{*}{$\begin{array}{l}\text { Education } \\
\text { (years) }\end{array}$} & $0-5$ & 153 (91.6\%) & 91 (58.0\%) & \multirow{3}{*}{$0.001^{* * *}$} \\
\hline & $5-10$ & $3(1.8 \%)$ & 27 (17.2\%) & \\
\hline & $10-15$ & $11(6.6 \%)$ & 39 (24.8\%) & \\
\hline \multirow[b]{2}{*}{$\begin{array}{l}\text { Marital } \\
\text { status }\end{array}$} & Married & 93 (55.7\%) & 84 (53.5\%) & \multirow[b]{2}{*}{0.693} \\
\hline & $\begin{array}{l}\text { Other } \\
\text { (single, } \\
\text { widow, } \\
\text { divorced) }\end{array}$ & 74 (44.3\%) & 73 (46.5\%) & \\
\hline \multirow{2}{*}{$\begin{array}{l}\text { Social } \\
\text { security }\end{array}$} & No & 2 (1.2\%) & 14 (8.9\%) & \multirow{2}{*}{$0.001^{* * *}$} \\
\hline & Yes & 165 (98.8\%) & 143 (92.3\%) & \\
\hline \multirow{2}{*}{$\begin{array}{l}\text { Working } \\
\text { status }\end{array}$} & Unemployed & 160 (95.8\%) & 111 (70.7\%) & \multirow{2}{*}{$0.001^{\star * \star x}$} \\
\hline & Employed & 7 (4.2\%) & $46(29.3 \%)$ & \\
\hline \multirow{4}{*}{$\begin{array}{l}\text { Who does } \\
\text { she/he live } \\
\text { with? }\end{array}$} & Single & $13(7.8 \%)$ & 7 (4.5\%) & \multirow{4}{*}{0.115} \\
\hline & Family & 144 (86.2\%) & 138 (87.9\%) & \\
\hline & $\begin{array}{l}\text { Friends- } \\
\text { Relatives }\end{array}$ & 7 (4.2\%) & 12 (7.6\%) & \\
\hline & $\begin{array}{l}\text { Institution- } \\
\text { caregiver }\end{array}$ & $3(1.8 \%)$ & $0(0.0 \%)$ & \\
\hline \multirow{2}{*}{ Smoking } & No & 158 (94.6\%) & 104 (66.2\%) & \multirow{2}{*}{$0.001^{\star * *}$} \\
\hline & Yes & 9 (5.4\%) & 53 (33.8\%) & \\
\hline \multirow{2}{*}{ Alcohol } & No & 164 (98.2\%) & 140 (89.2\%) & \multirow{2}{*}{$0.001^{* * *}$} \\
\hline & Yes & $3(1.8 \%)$ & 17 (10.8\%) & \\
\hline \multirow{2}{*}{$\begin{array}{l}\text { Use of } \\
\text { psychoactive } \\
\text { agents }\end{array}$} & No & $162(97.0 \%)$ & 143 (91.1\%) & \multirow{2}{*}{$0.023^{*}$} \\
\hline & Yes & 5 (3.0\%) & 14 (8.9\%) & \\
\hline \multirow{2}{*}{$\begin{array}{l}\text { Physical } \\
\text { disease }\end{array}$} & No & 83 (49.7\%) & 140 (89.2\%) & \multirow{2}{*}{$0.001^{* * *}$} \\
\hline & Yes & $84(50.3 \%)$ & 17 (10.8\%) & \\
\hline
\end{tabular}

$65 \%$. Ratios may be affected by variables such as the definition of recurrent admission, region where PES is located, and different cultures $(4,7)$. The ratio we determined was in parallel with the rates in other studies.

The level of education in the elderly was lower than in the young. Among the elderly who were admitted to PES, the rate of those receiving education for seven years and below was reported to be $32 \%$. The level of education may vary according to the region where the study was conducted $(11,12)$. Increasing the level of education can increase the awareness of the patients and provide a more effective solution to the problems. Again, the increased level of education may be effective in the implementation of preventive measures (prevention of diseases such as healthy nutrition, sports, social activity) before admitting to PES.

$57 \%$ of elderly patients who were admitted to PES were living with their families, 38\% were living alone, and only $61 \%$ of the elderly group had a supportive environment. It was reported that the rate of admission to emergency service was $60 \%$ higher in patients living alone compared to their spouses, and weak social support was found to be determinant in emergency service admissions

\begin{tabular}{|c|c|c|c|c|}
\hline & & $\begin{array}{l}65 \text { years } \\
\text { and over } \\
(n=167)\end{array}$ & $\begin{array}{l}\text { Between } \\
18-64 \\
(n=157)\end{array}$ & $p$ \\
\hline \multicolumn{2}{|c|}{ Number of admissions } & $2.46 \pm 0.99$ & $2.41 \pm 0.71$ & 0.356 \\
\hline \multirow{3}{*}{$\begin{array}{l}\text { Accompanying } \\
\text { during } \\
\text { admission }\end{array}$} & Single & $23(13.8 \%)$ & $88(56.1 \%)$ & \multirow{3}{*}{$0.001^{*}$} \\
\hline & $\begin{array}{l}\text { Family } \\
\text { member }\end{array}$ & $138(82.6 \%)$ & $58(36.9 \%)$ & \\
\hline & $\begin{array}{l}\text { Other (friends, } \\
\text { security staff, } \\
\text { etc.) }\end{array}$ & $6(3.6 \%)$ & $11(7.0 \%)$ & \\
\hline \multirow{3}{*}{$\begin{array}{l}\text { Admission } \\
\text { type }\end{array}$} & Direct & 155 (92.8\%) & 154 (98.1\%) & \multirow{3}{*}{0.076} \\
\hline & $\begin{array}{l}\text { External } \\
\text { referral }\end{array}$ & $5(3.0 \%)$ & 1 (0.6\%) & \\
\hline & Consultation & $7(4.2 \%)$ & $2(1.3 \%)$ & \\
\hline \multirow{2}{*}{$\begin{array}{l}\text { Admission for } \\
\text { prescribing } \\
\text { medication }\end{array}$} & No & 164 (98.2\%) & $153(97.5 \%)$ & \multirow{2}{*}{0.642} \\
\hline & Yes & $3(1.8 \%)$ & $4(2.5 \%)$ & \\
\hline \multirow{2}{*}{$\begin{array}{l}\text { Physical } \\
\text { examination }\end{array}$} & No & 155 (92.7\%) & 155 (98.7\%) & \multirow{2}{*}{$0.009^{*}$} \\
\hline & Yes & $12(7.2 \%)$ & $2(1.3 \%)$ & \\
\hline \multirow{2}{*}{ Consultation } & No & 134 (80.2\%) & 152 (96.8\%) & \multirow{2}{*}{$0.001^{*}$} \\
\hline & Yes & 33 (19.8\%) & $5(3.2 \%)$ & \\
\hline \multirow{2}{*}{$\begin{array}{l}\text { Treatment at } \\
\text { emergency } \\
\text { service }\end{array}$} & No & $114(68.3 \%)$ & $106(67.5 \%)$ & \multirow{2}{*}{0.885} \\
\hline & Yes & 53 (31.7\%) & 51 (32.5\%) & \\
\hline \multirow{2}{*}{ Treatment plan } & Outpatient & $126(75.4 \%)$ & $103(65.6 \%)$ & \multirow{2}{*}{0.052} \\
\hline & Inpatient & 41 (24.6\%) & $54(34.4 \%)$ & \\
\hline \multirow{2}{*}{$\begin{array}{l}\text { Treatment } \\
\text { arrangement }\end{array}$} & No & 53 (31.7\%) & 87 (55.4\%) & \multirow{2}{*}{$0.001^{*}$} \\
\hline & Yes & $114(68.3 \%)$ & $70(44.6 \%)$ & \\
\hline
\end{tabular}


Table 3. Disease duration, clinical symptoms and findings

\begin{tabular}{|c|c|c|c|c|}
\hline & & & & \\
\hline & $1-5$ years & $81(48.5 \%)$ & 78 (49.7\%) & \\
\hline & $5-10$ years & $14(8.4 \%)$ & $43(27.4 \%)$ & \\
\hline Disease period & $10-20$ years & 22 (13.2\%) & $28(17.8 \%)$ & $0.001^{\star \star *}$ \\
\hline & 20-30 years & 24 (14.4\%) & $7(4.5 \%)$ & \\
\hline & over 30 years & $26(15.6 \%)$ & $1(0.6 \%)$ & \\
\hline & No & 150 (89.8\%) & 130 (82.8\%) & \\
\hline Drug refusal & Yes & $27(10.2 \%)$ & 17 (17.2\%) & 0.065 \\
\hline & No & 97 (58.1\%) & $82(52.2 \%)$ & \\
\hline Decrease in sleep & Yes & 70 (41.9\%) & 75 (47.8\%) & 0.290 \\
\hline & No & 167 (100\%) & 156 (99.4\%) & \\
\hline Increase in sleep & Yes & 0 (0.00\%) & $1(0.60 \%)$ & 0.302 \\
\hline & No & 147 (88.0\%) & 138 (87.9\%) & \\
\hline Auditory hallucination & Yes & $20(12 \%)$ & $19(12.1 \%)$ & $0.9 / 2$ \\
\hline & No & $154(92.2 \%)$ & 155 (98.7\%) & \\
\hline Visual hallucination & Yes & $13(7.8 \%)$ & $2(1.3 \%)$ & $0.005^{\star \star}$ \\
\hline & No & $163(97.6 \%)$ & 152 (96.8\%) & \\
\hline Thought of suicide & Yes & $4(2.4 \%)$ & $5(3.2 \%)$ & 0.666 \\
\hline & No & 165 (98.8\%) & $151(96.2)$ & \\
\hline Suicide attempt & Yes & $2(1.2 \%)$ & $6(3.8 \%)$ & 0.128 \\
\hline & No & $138(82.6 \%)$ & $126(80.3 \%)$ & \\
\hline Unhappiness & Yes & $29(17.4)$ & 31 (19.7\%) & 0.582 \\
\hline & No & $111(66.5 \%)$ & 105 (66.9\%) & \\
\hline Distress & Yes & 56 (33.5\%) & 52 (33.1\%) & 0.937 \\
\hline & No & 162 (97\%) & 145 (92.4\%) & \\
\hline Fear of death & Yes & $5(3 \%)$ & $12(7.6 \%)$ & 0.061 \\
\hline & No & 152 (91.0\%) & 149 (94.9\%) & \\
\hline Loss of appetite & Yes & $15(9.0 \%)$ & $8(5.1 \%)$ & 0.173 \\
\hline & No & $167(100.0 \%)$ & $157(100.0 \%)$ & \\
\hline Increased appetite & Yes & $0(0.0 \%)$ & $0(0.0 \%)$ & - \\
\hline & No & $140(83.8 \%)$ & 106 (67.5\%) & \\
\hline Somatic complaint & Yes & $27(16.2 \%)$ & 51 (32.5\%) & $0.001^{\star \star \star}$ \\
\hline Social withdrawal & No & 161 (96.4\%) & 151 (96.2\%) & \\
\hline Social withdrawal & Yes & $6(3.6 \%)$ & $6(3.8 \%)$ & 0.913 \\
\hline & No & 149 (89.2\%) & 127 (80.9\%) & \\
\hline Hyperactivity & Yes & 18 (10.8\%) & 30 (19.1\%) & $0.035^{x}$ \\
\hline & No & 135 (80.8\%) & 122 (77.7\%) & 0.487 \\
\hline Persecution delusion & Yes & 32 (19.2\%) & 35 (22.5\%) & $0.48 /$ \\
\hline Reference delusion & No & 165 (98.8\%) & 148 (94.3\%) & $0024 *$ \\
\hline Reterence delusion & Yes & $2(1.2 \%)$ & $9(5.7 \%)$ & $0.024^{n}$ \\
\hline & No & 164 (98.2\%) & 156 (99.4\%) & \\
\hline Jalusic delusion & Yes & $3(1.8 \%)$ & $1(0.6 \%)$ & 0.345 \\
\hline & No & $167(100.0 \%)$ & $157(100.0 \%)$ & \\
\hline Ninilistic delusion & Yes & $0(0.0 \%)$ & $0(0.0 \%)$ & - \\
\hline & No & 165 (98.8\%) & 152 (96.8\%) & \\
\hline Grandiose delusion & Yes & $2(1.2 \%)$ & $5(3.2 \%)$ & $0.2 / 4$ \\
\hline & No & 154 (92.2\%) & $157(100.0 \%)$ & \\
\hline Memory Impairment & Yes & $13(7.8 \%)$ & $0(0.0 \%)$ & $0.001^{\star \star \star x}$ \\
\hline & No & 157 (94.0\%) & 154 (98.1\%) & \\
\hline Behavioral problem & Yes & $10(6.0 \%)$ & $3(1.9 \%)$ & 0.062 \\
\hline & No & $111(66.5 \%)$ & 129 (82.2\%) & \\
\hline Verbal violence & Yes & 56 (33.5\%) & $28(17.8 \%)$ & $0.001^{\star \star \star}$ \\
\hline & No & 134 (80.2\%) & 123 (78.3\%) & \\
\hline Physical violence & Yes & 33 (19.8\%) & 34 (21.7\%) & 0.674 \\
\hline
\end{tabular}




\section{Table 4. Psychiatric diagnosis distribution}

\begin{tabular}{|l|l|l|}
\hline & $\mathbf{6 5}$ years and over $(\mathbf{n = 1 6 7 )}$ & $\mathbf{1 8 - 6 5}$ years $(\mathbf{n = 1 5 7 )}$ \\
\hline Depression & $29(17.4 \%)$ & $37(23.6 \%)$ \\
\hline Anxiety disorder & $20(12.0 \%)$ & $19(12.1 \%)$ \\
\hline Bipolar mood disorder & $32(19.2 \%)$ & $46(29.3 \%)$ \\
\hline Psychosis & $41(24.6 \%)$ & $44(28.0 \%)$ \\
\hline Behavioral and psychological symptoms related to dementia & $39(23.4 \%)$ & $0(0.0 \%)$ \\
\hline Mental retardation and behavior problems & $2(1.2 \%)$ & $3(1.9 \%)$ \\
\hline Alcohol and/or substance use disorder & $1(0.6 \%)$ & $4(2.5 \%)$ \\
\hline Adverse effect due to drug use & $3(1.8 \%)$ & $4(2.5 \%)$ \\
\hline Chi-square test was performed. $* *$ p $<0.001$ & & $0.001 * \star *$ \\
\hline
\end{tabular}

(13). According to the results of our study, the majority of both groups were living with their families. Elderly people with loss of spouse are given care by their relatives (1). Even though the elderly were mostly living with their families, they were admitted to PES as recurrent. It is necessary to establish a system to determine the psychosocial and emotional needs of the elderly and the people with whom they live together, to provide them with education to increase their awareness and to produce the necessary solutions.

In the studies, it was stated that diagnosis and treatment were particularly difficult in elderly people with psychiatric diseases, and that these problems were complicated by comorbid diagnosis, multiple drug use and underlying psychosocial problems. It is emphasized that determination of organic etiological factors is vital $(6,14-18)$. In our study, we found that the rate of comorbidity, physical examination and consultation was higher in the elderly who had recurrent admission to PES compared to the younger ones. While this situation is an indicator of more detailed evaluation and examination in evaluating the elderly patient in PES, the fact that the elderly patient recurrently admitted to PES is questioning the effectiveness of this service. While evaluating the elderly patient in PES, the importance of detailed examination was emphasized in terms of characteristics such as medical condition of the patient, medications used, substance abuse, cognitive functions and behavior changes. It was emphasized that detailed and careful evaluation of the elderly patient was the first step of safe separation from the emergency unit, wellregulated treatment and good results. For elderly patients, it has been reported that PES should be multidisciplinary (such as psychiatrists, internal medicine specialists, family physicians, social workers, specialist nurses often need to be integrated to other health care professionals), and should be linked to medical, psychiatric and social facilities $(10,14,17)$. In PES in our country, the creation of units consisting of trained teams providing special services to the elderly will ensure effective management of admissions and avoid repeated application.

The elderly and young group had similar rates in terms of emergency treatment. The rate of drugs prescribed was higher in the elderly group as a result of emergency psychiatric evaluation. The decision of hospitalization was higher in young people (statistically significant borderline significance). This may indicate that the clinician evaluating the elderly in PES prioritizes the safety of the patient in terms of medical intervention, takes into consideration the service conditions and has difficulty in making the decision of admission. This difficulty may lead the elderly to refer to PES recurrently. Indeed, despite the low rates of admission to PES, it has been reported that the rate of admission is higher in comparison to older patients (16). Elderly patients who are admitted to PES should be established to provide post-emergent hospitalization, multidisciplinary service, effective, adequate safety, focused on solving problems and reliable discharge. In this way, the elderly admitted to PES can be hospitalized to the service when necessary and recurrent admission can be prevented by effective interventions. Our hospital is a private branch hospital and absence of geropsychiatric service can explain the low hospitalization rates.

Specific diagnosis rates of the elderly patients who were admitted to PES were $27-37 \%$ for cognitive disorders, $31-39 \%$ for mood disorders, $4-14 \%$ for anxiety disorders, $8-18 \%$ for psychotic disorders, $11-24 \%$ for substance use, 3-11\% for adjustment disorder and $8 \%$ for personality disorders. Cognitive, psychotic and bipolar disorder diagnoses were higher in elderly patients who were admitted to PES $(15,19,20)$. In another study in which the epidemiology of the elderly psychiatric patients admitted to the emergency department was investigated, substance abuse was found to be the most frequently diagnosed disorder with $27 \%$, neuroses with $26 \%$ and psychoses with $21 \%$. In another study of 118 elderly patients who presented to PES, $30 \%$ organic brain disease and $31 \%$ affective disorder-schizophrenia and other psychotic disorders were diagnosed (21). It was reported that the most frequently diagnosed diagnosis was dementia in patients admitted to the emergency department of geropsychiatry and if there is an additional psychiatric diagnosis, the probability of hospitalization is high (16). In elderly patients, behavioral or psychological symptoms related to delirium and/or dementia are the most common causes of PES admission. Urgent safety issues for both patient and staff coexist with diagnostic priorities in a setting not geared the first line non-pharmacological strategies of meetings psychosocial and emotional needs of patients. It has been reported that the development and implementation of successful methods to provide effective support and management 
of patients, their families and psychosocial and emotional problems due to dementia with behavioral and psychological symptoms may reduce the rate of recurrent admission, psychotropic drug use and hospitalization (22). In a study that examined socio-demographic, clinical and discharge status of elderly and young people who were admitted to PES, depression was the most common diagnosis in both groups and it was stated that $19.5 \%$ of the patients were diagnosed with dementia, the diagnosis of two or more medical diseases was more common, cognitive impairment was more common and moderate-severe functional impairment was reported (23). According to the results of our study, visual hallucinations, memory impairment and verbal violence are the most common diagnoses in the elderly, and psychosis, behavioral and psychological symptoms related to dementia, bipolar mood disorder, depression and anxiety disorder are the most frequent diagnoses in the elderly. In young people, bipolar mood disorder, psychosis, depression, anxiety disorder, and alcohol and/or substance use disorder are the most common. According to our results and findings, psychotic disorder cognitive problems, behavioral and psychological symptoms related to dementia are prominent in the elderly. However, the distribution of diagnoses in the elderly may very between studies. This difference may be affected by the characteristics of the sample included in the study, the study design (such as retrospective, prospective), the unit in which the study was performed (such as general hospital emergency service, PES), and the country and/or region where the study was conducted.

According to our findings, symptom profile and diagnosis distribution (psychotic disorder, cognitive problems and behavioral and psychological symptoms related to dementia) are compatible with the elderly patients admitted to PES recurrently. This group of patients is recurrently admitted to PES because of psychotic symptoms such as visual hallucinations, cognitive problems such as memory disorders, and behavior problems such as verbal violence. An elderly patient with cognitive impairment, psychotic symptoms and behavioral problems, the clinician and his team in PES conditions, the effective evaluation of the patient, the correct diagnosis, what can and should be done as behavioral or psychological interventions, when, how and what drug should be started and decision to receive an outpatient and/or inpatient treatment may be confronted with many problems such as the safe discharge from PES. Failure to resolve these problems properly may cause the patient and his/her relatives to admit to PES again.

When evaluating the elderly patient in PES, it is important to consider the medical, cognitive, psychiatric, functional and social areas in detail, and to allocate sufficient time for the family interview where the patient and the caregiver will also be evaluated. PES needs to be shaped to meet the needs of the elderly.

\section{Study Limitations}

The limitation of our study is that it is carried out from a single center, it is based on retrospective file records and it is based on the records of different evaluators.

\section{CONCLUSION}

Our findings and studies, elderly patients differ from young people in terms of physical disease comorbidity, physical examination, consultation request, symptom profile, diagnosis and treatment plan. The evaluation of the elderly patient will provide a multidisciplinary approach, the formation of professional teams in the field should be the main purpose. In this way, recurrent admissions of elderly people to PES can be prevented.

Ethics Committee Approval: Ethical committee approval was obtained from the Local Ethics Committee of İstanbul Bakırköy Prof. Dr. Mazhar Osman Mental Health and Neurological Diseases Training and Research Hospital (approval number: 6779, date: 03.02.2014).

Informed Consent: Retrospective study.

Peer-review: Externally peer-reviewed.

Author Contributions: Concept - D.I.; Design - D.I., M.Y., G.Y.Y.; Data Collection and/or Processing - D.I., Ö.Ç., M.Y., G.Y.Y., E.A.Y.; Analysis and/ or Interpretation - D.İ., Ö.Ç., M.Y., M.C.I., E.A.Y., N.K.; Literature Search D.I., M.C.I., N.K.; Writing Manuscript - D.I., Ö.Ç., G.Y.Y., N.K.

Conflict of Interest: The authors have no conflict of interest to declare.

Financial Disclosure: The authors declared that this study has received no financial support.

\section{REFERENCES}

1. Turkish Statistical Institute. Basic statistics, Population and Demography, Population Projections. Population by age group and gender. www.tuik. gov.tr

2. Sullivan PF, Bulik CM, Forman SD, Mezzich JE. Characteristics of repeat users of a psychiatric emergency service. Hosp Community Psychiatry 1993; 44: 376-80

3. Pasic J, Russo J, Roy-Byrne P. High utilizers of psychiatric emergency services. Psychiatr Serv 2005; 56: 678-84.

4. Richard-Lepouriel H, Weber K, Baertschi M, DiGiorgio S, Sarasin F, Canuto A. Predictors of recurrent use of psychiatric emergency services. Psychiatr Serv 2015; 66: 521-26.

5. Ellison JM, Blum N, Barsky AJ. Repeat visitors in the psychiatric emergency service: a critical review of the data. Hosp Community Psychiatry 1986; 37: 37-41.

6. Boyer L, Dassa D, Belzeaux R, Henry JM, Samuelian JC, BaumstarckBarrau K. et al. Frequent visits to a French psychiatric emergency service: diagnostic variability in psychotic disorders. Psychiatr Serv 2011; 62: 96670 .

7. Chaput YJ, Lebel MJ. Demographic and clinical profiles of patients who make multiple visits to psychiatric emergency services. Psychiatr Serv 2007; 58: 335-41.

8. Chaput Y, Beaulieu L, Paradis M, Labonté E. The elderly in the psychiatric emergency service (PES); a descriptive study. BMC Psychiatry 2011; 15; 11:111.

9. Walsh PG, Currier G, Shah MN, Lyness JM, Friedman B. Psychiatric emergency services for the U.S. elderly: 2008 and beyond. Am J Geriatr Psychiatry 2008; 16: 706-17.

10. Colenda CC, Greenwald BS, Crossett JH, Husain MM, Kennedy GJ. Barriers to effective psychiatric emergency services for elderly persons. Psychiatr Serv 1997; 48: 321-25.

11. Puryear DA, Lovitt R, Miller DA. Characteristics of elderly persons seen in an urban psychiatric emergency room. Hosp Community Psychiatry 1991; 42: 802-7.

12. Sawayama E, Takahashi M, Arai H, Nakajima K, Kano A, Sawayama T. et al. Characteristics of elderly people using the psychiatric emergency system. Psychiatry Clin Neurosci 2009; 63: 577-9.

13. Hastings SN, George LK, Fillenbaum GG, Park RS, Burchett BM, Schmader KE. Does lack of social support lead to more ED visits for older adults? Am J Emerg Med 2008; 26: 454-61. 
14. Thienhaus OJ, Piasecki MP. Assessment of geriatric patients in the psychiatric emergency service. Psychiatr Serv 2004; 55: 639-42.

15. Waxman HM, Carner EA, Dubin W, Klein M. Geriatric psychiatry in the emergency department: characteristics of geriatric and non-geriatric admissions. J Am Geriatr Soc 1982; 30: 427-32.

16. Thienhaus OJ, Rowe C, Woellert P, Hillard JR. Geropsychiatric emergency services: utilization and outcome predictors. Hosp Community Psychiatry 1988; 39: 1301-5.

17. Sikka V, Kalra S, Galwankar S. Psychiatric Emergencies in the Elderly. Emerg Med Clin North Am 2015; 33: 825-39.

18. Piechniczek-Buczek J. Psychiatric emergencies in the elderly population. Emerg Med Clin North Am 2006; 24: 467-90.

19. Stebbins LA, Hardman GL. A survey of psychiatric consultations at a suburban emergency room. Gen Hosp Psychiatry 1993; 15: 234-42.
20. Cully JA, Molinari VA, Snow AL, Burruss J, Kotrla KJ, Kunik ME. Utilization of emergency center services by older adults with a psychiatric diagnosis. Aging Ment Health 2005; 9: 172-6.

21. Hazlett SB, McCarthy ML, Londner MS, Onyike CU. Epidemiology of adult psychiatric visits to US emergency departments. Acad Emerg Med 2004; 11: 193-5.

22. Silwanowicz RM, Maust DT, Seyfried LS, Chiang C, Stano C, Kales HC. Management of older adults with dementia who present to emergency services with neuropsychiatric symptoms. Int J Geriatr Psychiatry 2017; 32: $1233-40$.

23. Seitz DP, Vigod SN, Lin E, Gruneir A, Newman A, Anderson G. et al. Characteristics of older adults hospitalized in acute psychiatric units in ontario: a population-based study. Can J Psychiatry 2012; 57: 554-63. 